\title{
CONFORMIDADE NO TEMPO DE REALIZAÇÃO DE EXAMES DE RADIOGRAFIA EM SETOR DE OBSERVAÇÃO CLÍNICA/CIRÚRGICA DO HOSPITAL MUNICIPAL DR. JOSÉ DE CARVALHO DE FLORENCE (HMJCF)
}

Eixo temático: Gestão em Saúde

INTRODUÇÃO: Os indicadores de qualidade são ferramentas que auxiliam na monitorização e tomada de decisões frentes a situações decorrentes'. Mediante ao conceito, a equipe de enfermagem e de radiologia constataram problemas na ausência de fluxo de entrega das solicitações de exames radiológicos e a falta de identificação completa dos pedidos, resultando na demora da realização das imagens, dificuldades ao técnico de radiologia em localizar o paciente e sobrecarga da enfermagem em encaminhar os pacientes ao setor, sendo que a meta para a realização da imagem é de 120 minutos.

\section{OBJETIVO:}

Aumentar a conformidade de tempo para realização dos exames de raio $x$ do setor verde de $53 \%$ para $\geq 70 \%$ em 12 meses.

\section{RESULTADOS:}

Foi criado um fluxo para a realização dos exames do setor verde com base em contramedidas como: identificação visual dos leitos, caixas específicas para o armazenamento dos pedidos e a inserção do técnico de radiologia na busca pelos pacientes para a realização do exame, o que manteve a conformidade acima dos $70 \%$ em todos os meses, chegando alguns meses índices acima de $90 \%$.

\section{METODOLOGIA:}

Análise dos indicadores de tempo para realização de exames de radiografia do setor verde utilizando o A3 (método Lean), no período de Setembro/2017 a Outubro/2018 no HMJCF.

\section{CONCLUSÃO:}

Mesmo com as intervenções realizadas notou-se que algumas situações, como problemas técnicos, impossibilitaram a estabilização da conformidade, levando a oscilações mês a mês. Porém com a análise dos indicadores mecanismos de intervenção são criados constantemente para manter o fluxo com o tempo adequado. Devido melhora do dado, percebe-se a necessidade de planejar um novo valor com o mínimo de $80 \%$ nos próximos meses.

REFERÊNCIAS: OLIVEIRA, L.S., COSTA, D.M.L., ALMEIDA, H.O.C., MENDONÇA, I.O. Indicadores de Qualidade nos Serviços de Urgência Hospitalar. Ciências Biológicas e de Saúde Unit, Aracajú, v.4, n.3, p.173-88. Abril de 2018. 